\title{
Characterization of Steel Slag Filler and Its Effect on Aging Resistance of Asphalt Mastic with Various Aging Methods
}

\author{
Minghua Wei ${ }^{1}$, Shaopeng $\mathrm{Wu}^{2, *}$, Haiqin $\mathrm{Xu}^{2, *}$, Hechuan $\mathrm{Li}^{3}$ and Chao Yang ${ }^{2}$ D \\ 1 School of Transportation, Wuhan University of Technology, Wuhan 430070, China; weiminghua@whut.edu.cn \\ 2 State Key Laboratory of Silicate Materials for Architectures, Wuhan University of Technology, \\ Wuhan 430070, China; hbyangc@whut.edu.cn \\ 3 Faculty of Engineering, China University of Geosciences, Wuhan 430074, China; lihechuan@cug.edu.cn \\ * Correspondence: wusp@whut.edu.cn (S.W.); xuhaiqin@whut.edu.cn (H.X.)
}

check for

updates

Citation: Wei, M.; Wu, S.; Xu, H.; Li, H.; Yang, C. Characterization of Steel Slag Filler and Its Effect on Aging Resistance of Asphalt Mastic with Various Aging Methods. Materials 2021, 14, 869. https:// doi.org/10.3390/ma14040869

Received: 8 January 2021

Accepted: 5 February 2021

Published: 11 February 2021

Publisher's Note: MDPI stays neutral with regard to jurisdictional claims in published maps and institutional affiliations.

Copyright: (c) 2021 by the authors. Licensee MDPI, Basel, Switzerland. This article is an open access article distributed under the terms and conditions of the Creative Commons Attribution (CC BY) license (https:/ / creativecommons.org/licenses/by/ $4.0 /)$.

\begin{abstract}
Steel slag is the by-product of the steelmaking industry, the negative influences of which prompt more investigation into the recycling methods of steel slag. The purpose of this study is to characterize steel slag filler and study its feasibility of replacing limestone filler in asphalt concrete by evaluating the resistance of asphalt mastic under various aging methods. Firstly, steel slag filler, limestone filler, virgin asphalt, steel slag filler asphalt mastic and limestone filler asphalt mastic were prepared. Subsequently, particle size distribution, surface characterization and pore characterization of the fillers were evaluated. Finally, rheological property, self-healing property and chemical functional groups of the asphalt mastics with various aging methods were tested via dynamic shear rheometer and Fourier transform infrared spectrometer. The results show that there are similar particle size distributions, however, different surface characterization and pore characterization in the fillers. The analysis to asphalt mastics demonstrates how the addition of steel slag filler contributes to the resistance of asphalt mastic under the environment of acid and alkaline but is harmful under UV radiation especially. In addition, the pore structure in steel slag filler should be a potential explanation for the changing resistance of the asphalt mastics. In conclusion, steel slag filler is suggested to replace limestone filler under the environment of acid and alkaline, and environmental factor should be taken into consideration when steel slag filler is applied to replace natural fillers in asphalt mastic.
\end{abstract}

Keywords: steel slag filler; characterization; asphalt mastic; aging methods; resistance

\section{Introduction}

On account of the outstanding performances of asphalt mixtures, asphalt pavements have been widely used in road construction. Generally, asphalt pavements are considered as a system of coarse aggregates, fine aggregates and asphalt mastic in previous research [1,2]. In the system, the addition of fillers to bitumen forms the asphalt mastic, which fills the interstices between aggregates and enhances the bonding performance [3]. Former research has demonstrated that it is the properties of asphalt mastics that influence the resistance to high-temperature deformation and low-temperature cracking of asphalt mixtures $[4,5]$. Due to the multiple functions of the fillers in asphalt mastic, the qualities of fillers have a significant impact on the asphalt mixture [6]. Nevertheless, the advancement of road construction projects in China, especially on the highway, has consumed consequential high-quality mineral fillers, which requires the novel substitution of analogous properties to replace natural mineral fillers urgently [7].

Steel slag, the main by-product in the steel-making industry, accounts for over $10 \%$ of crude steel production in the world [8,9]. However, the negative impact of steel slag on the environment, including occupation of the field, secondary pollution to water and soil and potential pollution of the heavy metal, demands the rescue and management of steel slag as soon as possible $[10,11]$. Fortunately, the properties of high abrasion resistance, tough 
surface characteristics, strong alkalinity and outstanding mechanical properties contribute to the application of steel slag as aggregates in asphalt concrete [12-14]. In comparison to natural aggregates, such as basalt, limestone and diabase, the high abrasion resistance and the tough surface characteristics of steel slag increase the skid resistance of asphalt pavement sharply [15]. Meanwhile, the strong alkalinity of steel slag enhances the "bond" in the aggregate-asphalt system, which improves the anti-water damage performances of asphalt concrete [16-18]. Moreover, recycling of steel slag as aggregate in asphalt pavement can subside the continuous demand of natural aggregates availably, limit the negative influence of steel slag on environment and even decrease the cost and energy consumption of road construction in certain degree [19]. These advantages make steel slag a superior substitute for natural aggregates.

Nonetheless, previous research on the recycling of steel slag in asphalt concrete attracts concern for, mainly, the properties of asphalt pavement with steel slag replacing coarse aggregates and fine aggregates; research on the properties of asphalt pavement with steel slag fillers(SSF) replacing the fillers is scarce. At present, the research focuses on the properties of asphalt mastics with SSF replacing natural mineral fillers in a regular environment. Li et al. [20] discussed the effect of steel slag filler milled from raw steel slag with different particle sizes on rheological properties of asphalt mortar and claimed that steel slag fillers can be used as potential materials to replace limestone fillers. Tao et al. [21] came to a similar conclusion and proposed that the steel slag fillers content should be lower than $75 \%$ by volume. Kong et al. [22] selected different basic oxygen furnace slag filler to investigate its influence on properties of asphalt mastic and the results showed the fillers could increase high temperature anti-rutting stability of asphalt concrete but reduce low-temperature flow performance of asphalt mastic. Notwithstanding, the performance of asphalt mastics with SSF stand a good chance of differing from that with limestone fillers (LF) under different aging methods, due to the fact that the pore-structure of steel slag has the potential to reflect less energy and refract more energy more easily [23]. In addition, the reaction between different environment and sufficient $\mathrm{f}-\mathrm{CaO}$ in SSF can cause the confusion of reacted order, such as in acid, alkali, $\mathrm{NaCl}$ and pure water environment, which correspond to the area of acid rain, salt lick and normalization [24-26]. Meanwhile, the environment of heat, oxygen and ultraviolet also should be taken into the consideration [27]. Therefore, it is significant to figure out the environmental influence on the asphalt mastics with SSF and the difference with the asphalt mastics with LF.

This research aims to study the feasibility of SSF replacing LF in asphalt concrete by evaluating the resistance of asphalt mastic under various aging methods. Firstly, the particle size distribution, surface characterization and pore characterization of SSF and LF were evaluated. Virgin asphalt (VA), steel slag filler asphalt mastic (SSFA) and limestone filler asphalt mastic (LFA) were prepared. Then, solution aging (acid solution/alkali solution/ $\mathrm{NaCl}$ solution/pure water), thin-film oven test (TFOT) aging, UV aging and TFOT+UV aging were applied to the asphalt mastics. The rheological property, self-healing property and chemical functional groups of SSFA and LFA with various aging methods were tested, respectively.

\section{Materials and Specimens Preparation}

\subsection{Raw Materials}

In this research, the commonly used bitumen (AH-70 asphalt), provided from Guochuang Co., Ltd.,Wuhan, Hubei, China, was used as binder in asphalt mastic. Steel slags with a particle size of 2.36-4.75 mm, supplied from Baotou Iron and Steel (Group) Co. Ltd., Baotou, Inner Mongolia, China, were selected to prepare steel slag fillers (SSF). The basic properties of AH-70 asphalt and steel slag can be seen in Table 1. 
Table 1. Properties of AH-70 asphalt and steel slag.

\begin{tabular}{cccc}
\hline Materials & Properties & Values & Specifications [28] \\
\hline \multirow{4}{*}{ AH-70 asphalt } & Penetration $\left(25^{\circ} \mathrm{C}, 0.1 \mathrm{~mm}\right)$ & 63.6 & $60 \sim 80$ \\
& Ductility $\left(15^{\circ} \mathrm{C}, \mathrm{cm}\right)$ & $>100$ & $\geq 40$ \\
& Softening point $\left({ }^{\circ} \mathrm{C}\right)$ & 47.8 & 43 \\
& Density $\left(\mathrm{g} / \mathrm{cm}^{3}\right)$ & 1.035 & - \\
& Fine aggregate density $\left(\mathrm{g} / \mathrm{cm}^{3}\right)$ & 3.56 & $\geq 2.9$ \\
Steel slag & Coarse aggregate density $\left(\mathrm{g} / \mathrm{cm}^{3}\right)$ & 3.65 & $\geq 2.9$ \\
& Los Angeles abrasion & 8.3 & $\leq 28$ \\
& Crush values & 12.9 & $\leq 26$ \\
\hline
\end{tabular}

Steel slags were crushed through the ball mill for $25 \mathrm{~min}$ and sieved into fillers with a particle size less than $0.075 \mathrm{~mm}$. As the reference fillers for comparison with SSF, limestone fillers (LF) were purchased from Maliang Aggregates, Jingmen, China. The basic properties of the fillers are shown in Table 2 [29].

Table 2. Properties of steel slag fillers and limestone fillers.

\begin{tabular}{crcc}
\hline \multicolumn{2}{c}{ Properties } & Steel Slag Fillers & Limestone Fillers \\
\hline \multicolumn{2}{c}{ Apparent specific gravity $\left(\mathrm{g} / \mathrm{cm}^{3}\right)$} & 3.640 & 2.708 \\
\hline \multirow{2}{*}{ Size range } & $<0.6 \mathrm{~mm}$ & 100 & 100 \\
& $<0.15 \mathrm{~mm}$ & 100 & 99.2 \\
& $<0.075 \mathrm{~mm}$ & 100 & 94.6 \\
\hline
\end{tabular}

\subsection{Preparation of Asphalt Mastic}

In this study, AH-70 asphalt, SSF and LF were chosen to prepare asphalt mastic. The consumption of asphalt and fillers were determined by a qualified mix proportion of asphalt concrete meanwhile asphalt aggregate ratio was $4.9 \%$. Therefore, the volume ratio of fillers to asphalt was determined as 0.3.

Preparation steps of asphalt mastic were as follows:

1. The asphalt and fillers were heated to target temperatures in the oven (AH-70 asphalt of $120^{\circ} \mathrm{C}$ and fillers of $150{ }^{\circ} \mathrm{C}$ );

2. Then, asphalt was removed to the containers kept in an oil bath to hold the temperature. Asphalt was pre-mixed with rotating speed limited at $500 \mathrm{rpm}$ for $5 \mathrm{~min}$;

3. Fillers were added into a container gradually with consistent rotating speed. Until all the fillers were added, the speed was increased to $1500 \mathrm{rpm}$ for $10 \mathrm{~min}$;

4. Finally, asphalt mastic was transferred to other containers for storage.

5. Eventually, virgin asphalt (VA), steel slag fillers asphalt mastic (SSFA) and limestone fillers asphalt mastic (LFA) were prepared.

\section{Research Methods}

\subsection{Material Characteristics of Fillers}

The particle size distribution of the fillers was evaluated by laser particle size analyzer, Mastersizer 2000, Malvern panalytical, Malvern, UK. A scanning electron microscope, QUANTA FEG 450, made by FEI, Hillsboro, OR, USA, was used to characterize the surface characteristics of the two fillers. To obtain the characteristics of the pores in the fillers, samples were measured by ASAP 2020M manufactured by Micromeritics, Norcross, GA, USA.

\subsection{Aging Methods}

\subsubsection{TFOT Short-Term Aging}

In accordance with the "Standard Test of Bitumen and Bituminous Mixtures for Highway Engineering" (JTG E20-2011) [28], the samples after short-term thermal aging were obtained by the thin-film oven test (TFOT). The conditions of standardization were $(163 \pm 1){ }^{\circ} \mathrm{C}$ for $5 \mathrm{~h}$. 


\subsubsection{Ultraviolet Aging}

Ultraviolet (UV) aging was conducted after the short-term aging, the asphalt mortars were placed into the oven at $50{ }^{\circ} \mathrm{C}$ for UV aging, within a period of 3 days. The UV radiation was reached to $50 \mathrm{w} / \mathrm{m}^{2}$.

\subsubsection{Solution Aging}

Acid solution ( $\mathrm{H} 2 \mathrm{SO} 4 / \mathrm{HNO} 3 /$ water solution, $\mathrm{pH}=3)$, alkali solution $(\mathrm{NaOH}$ solution, $\mathrm{pH}=11$ ), $10 \mathrm{wt} . \% \mathrm{NaCl}$ solution (Sinopharm Chemical Reagent co.,Ltd, Shanghai, China) and pure water were used to perform solution aging. Asphalt mastics of $6 \mathrm{~g}$ were taken out to the glass dish with the radius of $49 \mathrm{~mm}$ and the height of $18 \mathrm{~mm}$, then kept in the oven at $150{ }^{\circ} \mathrm{C}$ for half an hour to cover the bottom of the dish. Then, the samples of asphalt mastic with the thickness of about $0.76 \mathrm{~mm}$ were prepared. Solutions of $40 \mathrm{~mL}$ were poured into the dish to submerge the asphalt mastics, and the solutions were renewed every two days to keep the stability of $\mathrm{pH}$ value. After the aging of ten days, the samples were cleaned by pure water and kept in the oven of $150{ }^{\circ} \mathrm{C}$ for half an hour to remain dry. SSFA and LFA aged by acid solution, alkali solution, $\mathrm{NaCl}$ solution and pure water were named, respectively, SSFA-1, SSFA-2, SSFA-3 and SSFA-4; LFA-1, LFA-2, LFA-3 and LFA-4.

\subsection{Rheological Properties Test}

In this research, the rheological property of the asphalt mastics was tested by Dynamic Shear Rheometer (DSR), MCR101, Anton Paar, Graz, Austria. Temperature sweep was performed firstly in the range of $30^{\circ} \mathrm{C}$ to $80^{\circ} \mathrm{C}$ fixed at $10 \mathrm{rad} / \mathrm{s}$. Then, the frequency sweep was performed at the same temperature range to temperature sweep. Twelve temperature levels were obtained at temperature interval of $5{ }^{\circ} \mathrm{C}$. After reaching target temperature, the samples were scanned in therange of $0.1 \sim 100 \mathrm{~Hz}$ of frequency.

\subsection{Chemical Structure Test}

The chemical structures of VA and extractive asphalt mastics before and after the agings were evaluated by a Fourier transform infrared spectrometer (FTIR, Nexus, ThermoNicolet Crop., Waltham, MA, USA). In this paper, FTIR tests were performed under a scanned range between 4000 and $400 \mathrm{~cm}^{-1}$ and the scanning resolution was $4 \mathrm{~cm}^{-1}$.

\subsection{Experimental Plan}

The experimental plan is shown in Figure 1.

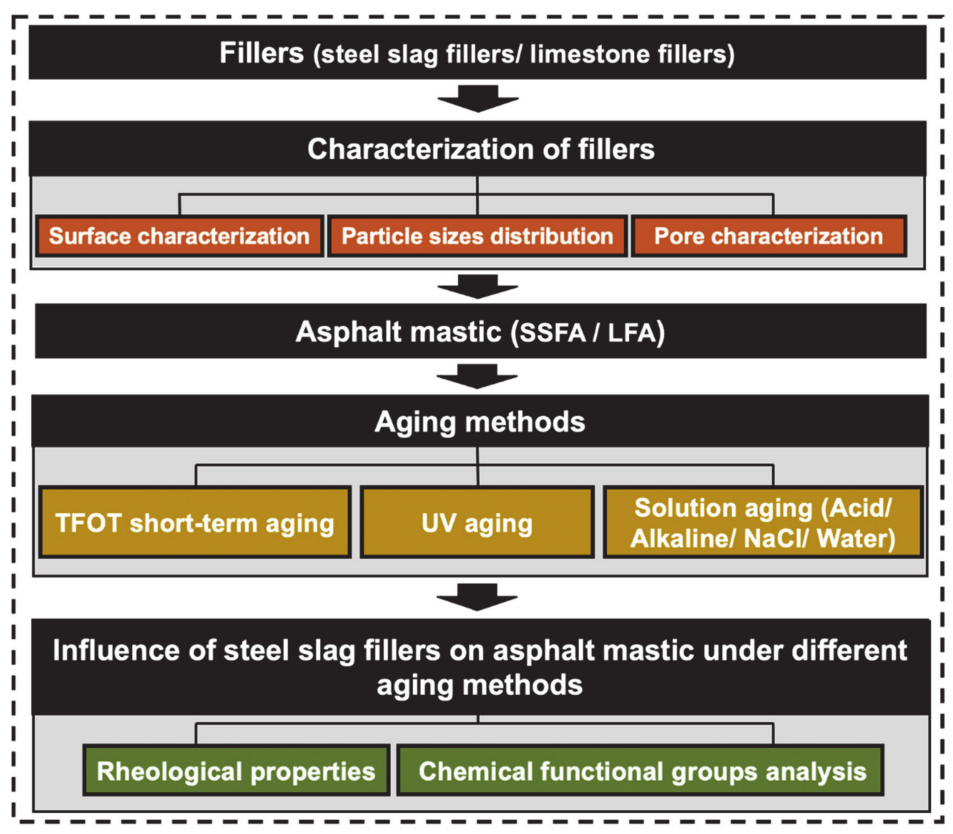

Figure 1. The flow chart of this research. 


\section{Results and Discussion}

\subsection{Characterization of Fillers}

\subsubsection{Particle Size Distribution Analysis}

Particle size distribution analysis of the fillers (SSF and LF) are shown in Figure 2. The particle size distribution of LF is at the range of around $0.3 \mu \mathrm{m}$ to $60 \mu \mathrm{m}$ and that of SSF is at the range of around $0.3 \mu \mathrm{m}$ to $100 \mu \mathrm{m}$. The particle size of SSF is more concentrated at the range of around $0.3 \mu \mathrm{m}$ to $0.8 \mu \mathrm{m}$ and $30 \mu \mathrm{m}$ to $100 \mu \mathrm{m}$ while particle size of LF is more concentrated at the range of around $6 \mu \mathrm{m}$ to $30 \mu \mathrm{m}$. At the residual range (round 0.8 $\mu \mathrm{m}$ to $6 \mu \mathrm{m}$ ), the distribution of the fillers is similar significantly. In general, the particle size distribution of SSF and LF presents similitude, especially at the range from $0.3 \mu \mathrm{m}$ to $10 \mu \mathrm{m})$. However, the distinction in the particle sizes distribution indicates SSF possessed more uniformed distribution than LF. The uniformity might be caused by the method of grinding by manual in laboratory. Moreover, the resemblance in particle size distribution of the fillers contributes to the replacement of SSF to LF as fillers in asphalt concentrate from the perspective of gradation.

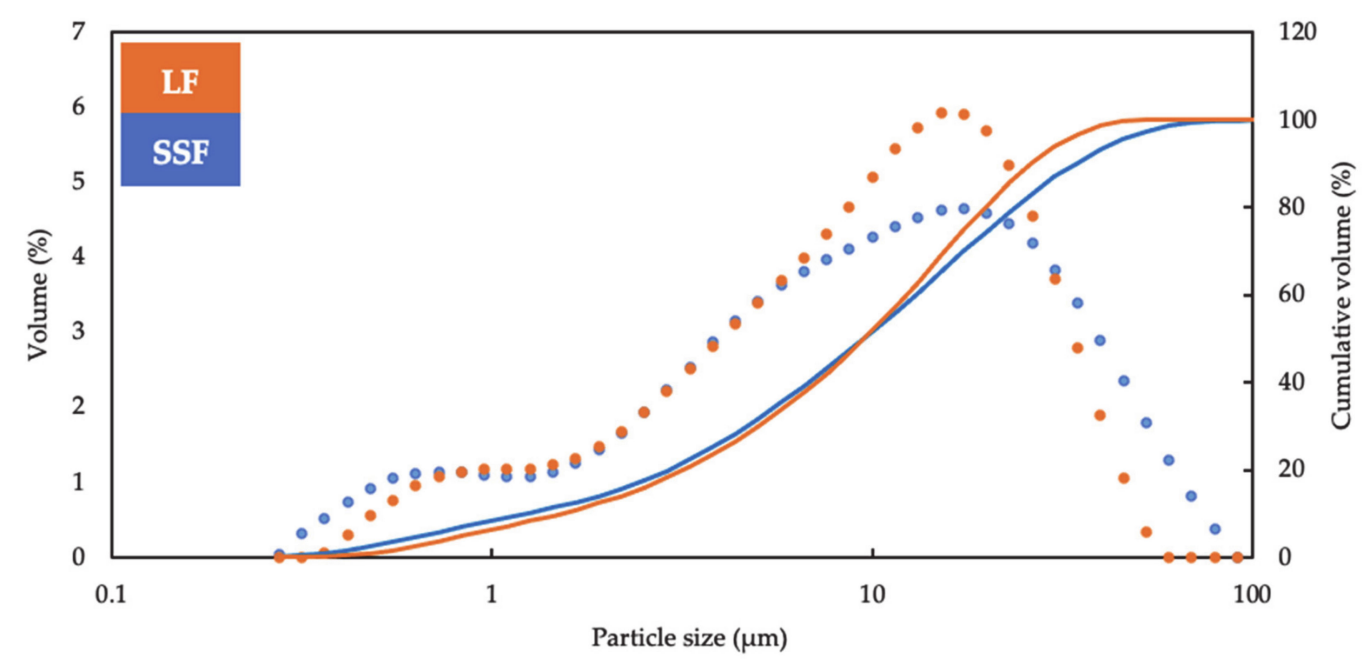

Figure 2. Particle size distribution of SSF and LF.

\subsubsection{Surface Characterization}

The surface characterizations of SSF and LF tested through SEM method are shown in Figure 3. The surface of the SSF is observed to be rugged, which leads to an increase in cohesion between asphalt binder and fillers. Conversely, the surface of LF is markedly smoother than that of SSF, in which the former is less irregular-shaped, rough, and bumpy. These characterizations might have a negative impact on effective cohesion with asphalt binder and accordingly lead to poorer strength and water resistance. The raw materials of the fillers could account for their totally different surface characterization. SSF is obtained from steel slag whose surface remained rough and adhered numerous tiny particles though steel slag is grounded into filler, while LF is obtained by crushing limestone. Analogous to the application of steel slag in asphalt concrete, the unique surface characterizations of SSF could cause an increased consumption in the amount of asphalt required when applied in asphalt concrete. However, the usage of SSF is not supposed to increase the practical cost due to the fact that steel slag is actually considered as solid waste with cheapness.

\subsubsection{Pore Characterization}

The quantification of pore characterizations about SSF and LF is shown in Table 3. The surface area could present the number of pores in the fillers, and the BET model that was accepted most widely is selected to calculate the surface area. Compared to LF, there is nearly $100 \%$ increment of BET surface area in SSF. Similarly, the single point adsorption 
total volume of pores in SSF is more than that in LF- $0.006174 \mathrm{~cm}^{3} / \mathrm{g}$ as opposed to $0.002228 \mathrm{~cm}^{3} / \mathrm{g}$. Furthermore, less obvious changes are recorded in the BJH desorption average pore diameter of the fillers, where the values remain relatively unchanged orders of magnitude but differed greatly. The values have also confirmed the appearance shown in Figure 3. Figure 4 describes the pore distribution of SSF and LF. The dV/dD pore volume in SSF fluctuates violently between $17 \AA$ and $100 \AA$, during which the maximum had risen above $0.00001 \mathrm{~cm}^{3} / \mathrm{g} . \AA$. The trends for the $\mathrm{dV} / \mathrm{dD}$ pore volume in $\mathrm{LF}$ are almost the same, though their figures have obvious difference, with the former always standing larger than the latter. The closed area of the curves demonstrates the total pore volume of the fillers, which indicates more possession of pores in SSF. Furthermore, BET is the acronym of S. Brunauer, P. Emmett and E. Teller who proposed multi-molecular layer adsorption theory; $\mathrm{BJH}$ is a model named after the names of Barret, Joyner, and Halenda.

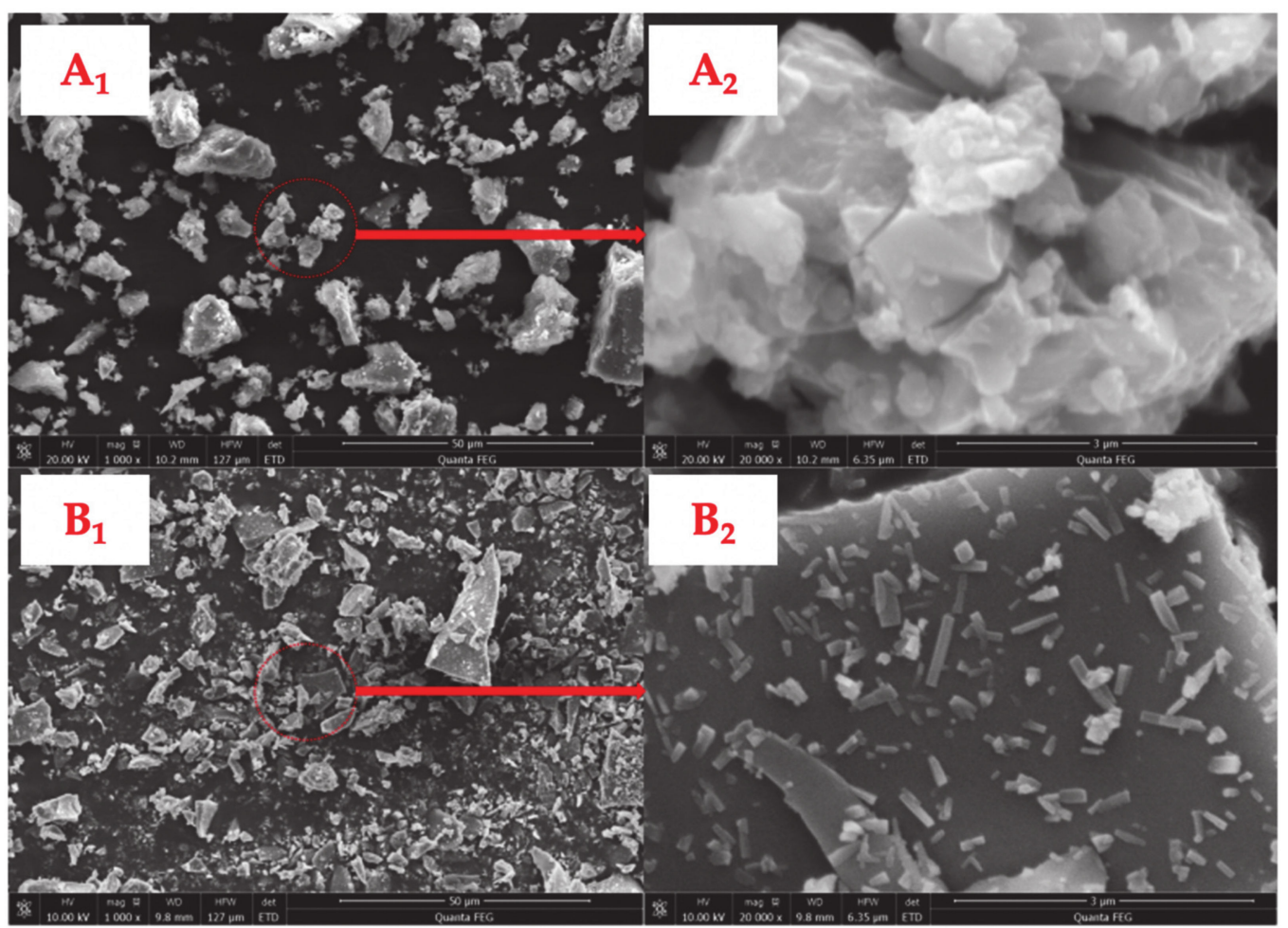

Figure 3. Surface characterization of fillers: SSF $\left(\mathbf{A}_{1}, \mathbf{A}_{2}\right)$ and $\operatorname{LF}\left(\mathbf{B}_{1}, \mathbf{B}_{2}\right)$.

Table 3. Pore characteristics of SSF and LF.

\begin{tabular}{cccc}
\hline Pore Characteristics & Units & SSF & LF \\
\hline BET surface area & $\mathrm{m}^{2} / \mathrm{g}$ & 1.2906 & 0.6448 \\
Single point adsorption total pore volume of pores & $\mathrm{cm}^{3} / \mathrm{g}$ & 0.006174 & 0.002228 \\
BJH desorption average pore diameter (4 V/A) & $\AA$ & 180.211 & 138.726 \\
\hline
\end{tabular}

\subsection{Influence of Steel Slag Fillers on Asphalt Mastic of Rheological Properties}

Figure 5 illustrates the results of temperature sweep analysis of VA, SSFA and LFA. It can be inferred that complex modulus of VA is the least while phase angle of VA is the most, which means VA has the minimum stiffness and most viscous components. Meanwhile, the similarity of the complex modulus and phase angle of SSF and LF is significantly obvious though there is still a slight difference. SSF possesses a larger complex modulus but lower phase angle. Compared to VA, a higher complex modulus of both SSF and LF indicates that the application of fillers heightened the resistance of the asphalt mastic to high-temperature deformation. Moreover, the slightly discrepancy of SSF and LF in rheological properties might be caused by the different characterization of fillers, especially 
the pore characterization and the raw materials. The characteristic with more pores of SSF has the potential to cause preferable absorption and combination with asphalt, which contributes to the increment in the complex modulus. In addition, the raw material of SSF is in stark contrast with that of LF: steel slag is rigid abundantly as far as the hardness is concerned. The rutting resistance of asphalt mortar is quantified by the rutting factor, which is expressed as $\mathrm{G}^{*} / \sin \delta$ and related to the high-performance resistance of asphalt concrete. The fatigue factor, expressed as $G^{*} \sin \delta$, the speed of energy loss under repeated loading. The fatigue damage and lifetime of an asphalt mixture have a proportional relationship with the energy loss during a cyclic loading process [30]. As shown in Figure 6, the rutting factor of SSFA and LFA is larger than that of VA, meanwhile the trends for rutting factor and fatigue factor of the samples are almost the same. It demonstrates that all samples containing fillers own better rutting resistance than that of VA. Furthermore, SSFA possesses similar but slightly superior resistances than that of LFA, which is conducive for SSF to the replacement of the fillers in asphalt concrete. This should be considered as a result of the chemical effect by alkaline compositions in SSF and asphaltic acid in asphalt. The stiffness of SSF also contributes to a more stable structure in the asphalt mastic and moreover better resistance.

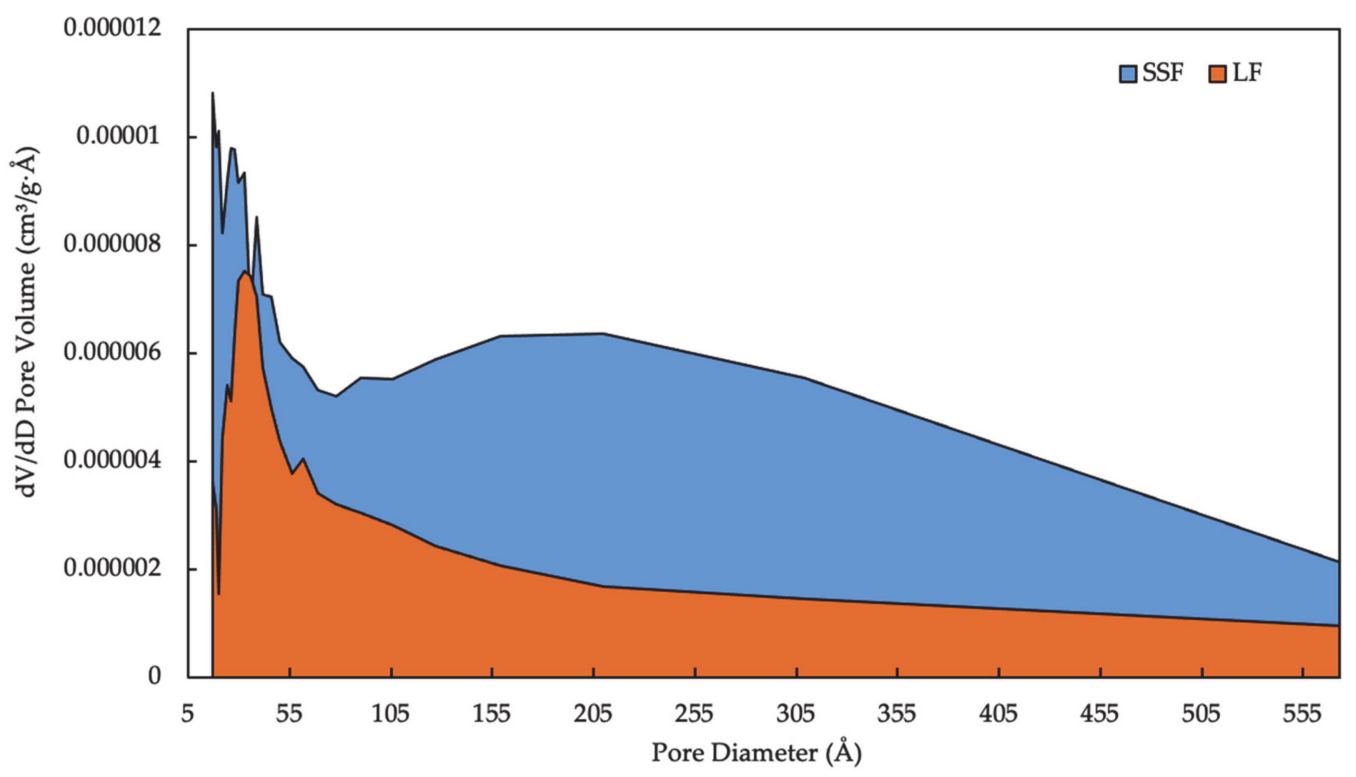

Figure 4. Pores distribution of SSF and LF.

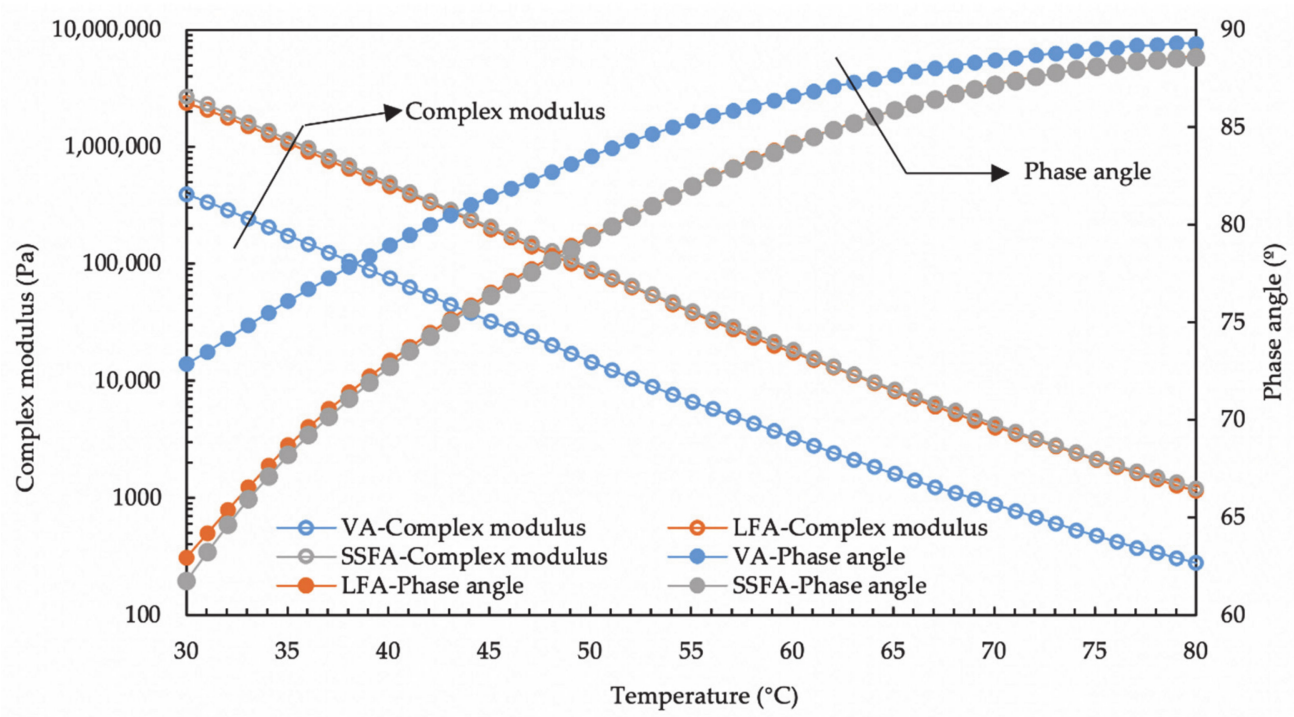

Figure 5. Temperature sweep analysis of VA, SSFA and LFA. 


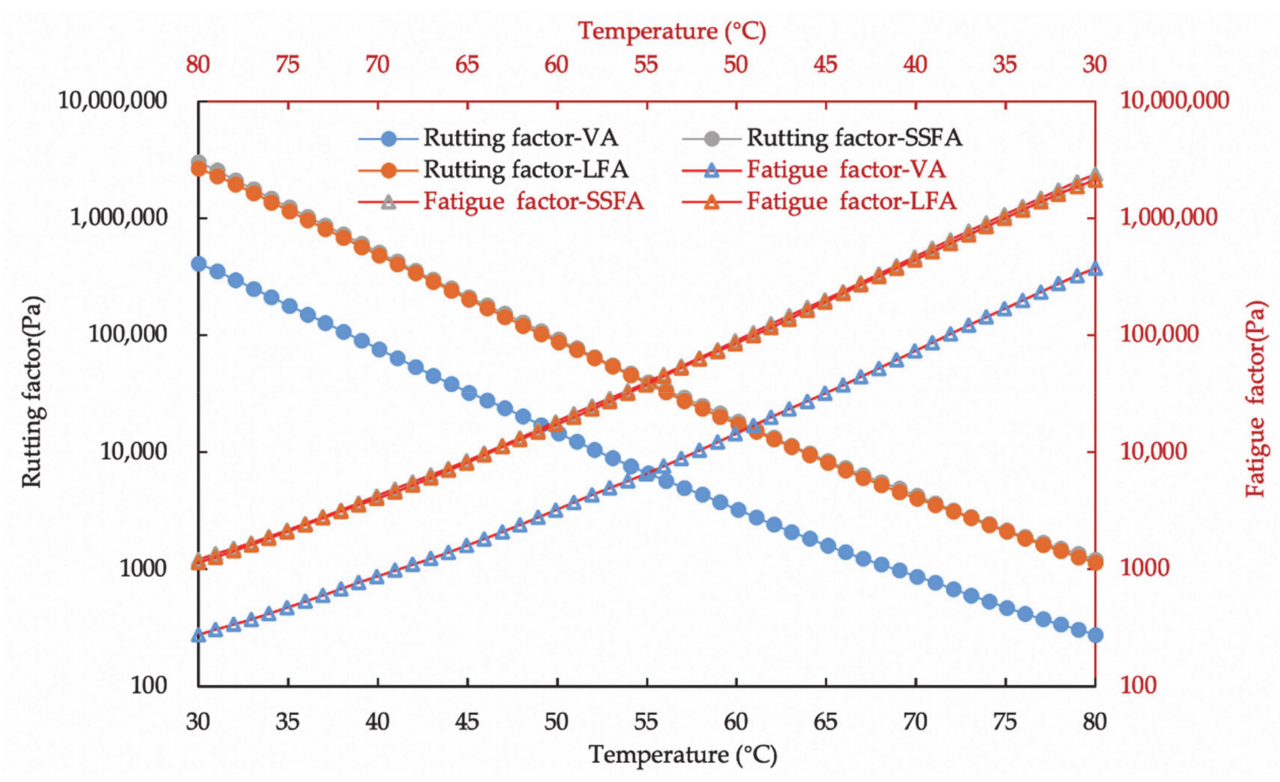

Figure 6. Rutting factor and fatigue factor of VA, SSFA and LFA.

4.3. Influence of Steel Slag Fillers on Asphalt Mastic under Different Aging Methods and Its Mechanism

\subsubsection{Rheological Properties}

The complex modulus and phase angles of SSFA and LFA conditioned by different solutions to simulate the impact by four kinds of environment for ten days are shown in Figure 7. The differentia in the rheological properties can reflect the ageing states of the bitumen. During the aging process, the rheological properties of SSFA and LFA change obviously; the complex modulus of asphalt mastic increases, meanwhile the phase angles decreases. The order of the complex modulus of SSFA is SSFA-3 > SSFA-2 > SSFA-4 > SSFA-1, and that of LFA is LFA-2 > LFA-3 > LFA-1 > LFA-4. The complex modulus values of SSFA after the aging of $\mathrm{NaCl}$ solution and pure water are higher than that of LFA, while the situation is reversed under acid solution and alkaline solution. In addition, the order of the changing trend of the phase angle is consistent with the complex modulus. After the aging of $\mathrm{NaCl}$ solution and pure water, rather than the aging of acid solution and alkaline solution, the phase angles of SSFA are smaller compared to LFA. The results show that, as compared to LFA, the negative impacts of $\mathrm{NaCl}$ solution and pure water on SSFA about the rheological properties are more serious than acid solution and alkaline solution.

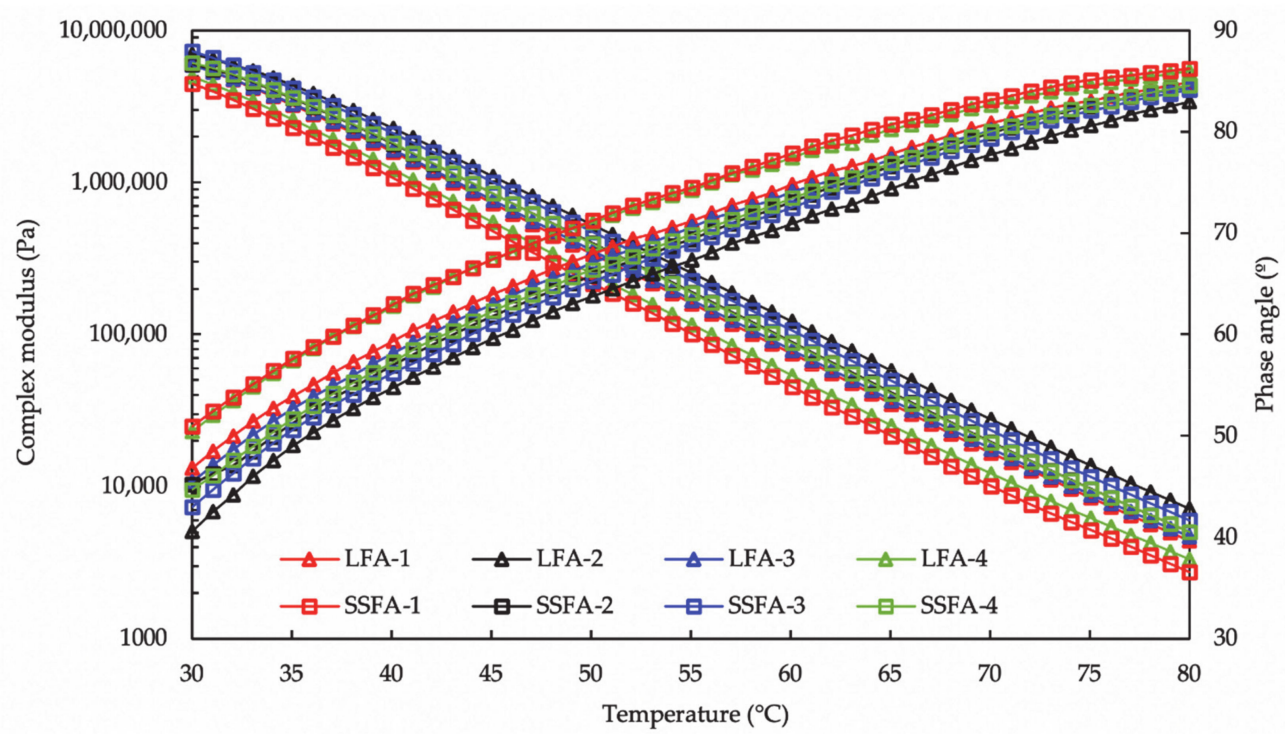

Figure 7. Temperature sweep analysis of SSFA and LFA after solution aging. 
The complex modulus and the phase angle of the asphalt mastic after the aging process to that of the asphalt mastic before the aging process are applied to characterize the complex modulus and the phase angle changes during the aging process. According to Equations (1) and (2), the two rheological aging indexes are calculated.

$$
\begin{gathered}
\text { Complex modulus aging index }=\frac{\text { Aged complex modulus }}{\text { Unaged complex modulus }} \times 100 \% \\
\text { Phase angle aging index }=\frac{\text { Aged phase angle }}{\text { Unaged phase angle }} \times 100 \%
\end{gathered}
$$

The results in the rheological aging indexes of SSFA and LFA before and after aging are shown in Figure 8. With the increment of temperature, the complex modulus aging index shows a gradual upward trend from $30{ }^{\circ} \mathrm{C}$, reaches a temporary peak at the range of $60{ }^{\circ} \mathrm{C}$ to $70{ }^{\circ} \mathrm{C}$, and then gradually decreases. This might be due to the fact that a temperature barrier existed at the range of $60^{\circ} \mathrm{C}$ to $70{ }^{\circ} \mathrm{C}$, and the index would approach 1 once the barrier is broken. As for the phase angle aging index, it presents a similar trend of increasing and a different trend of approaching and concentrating.

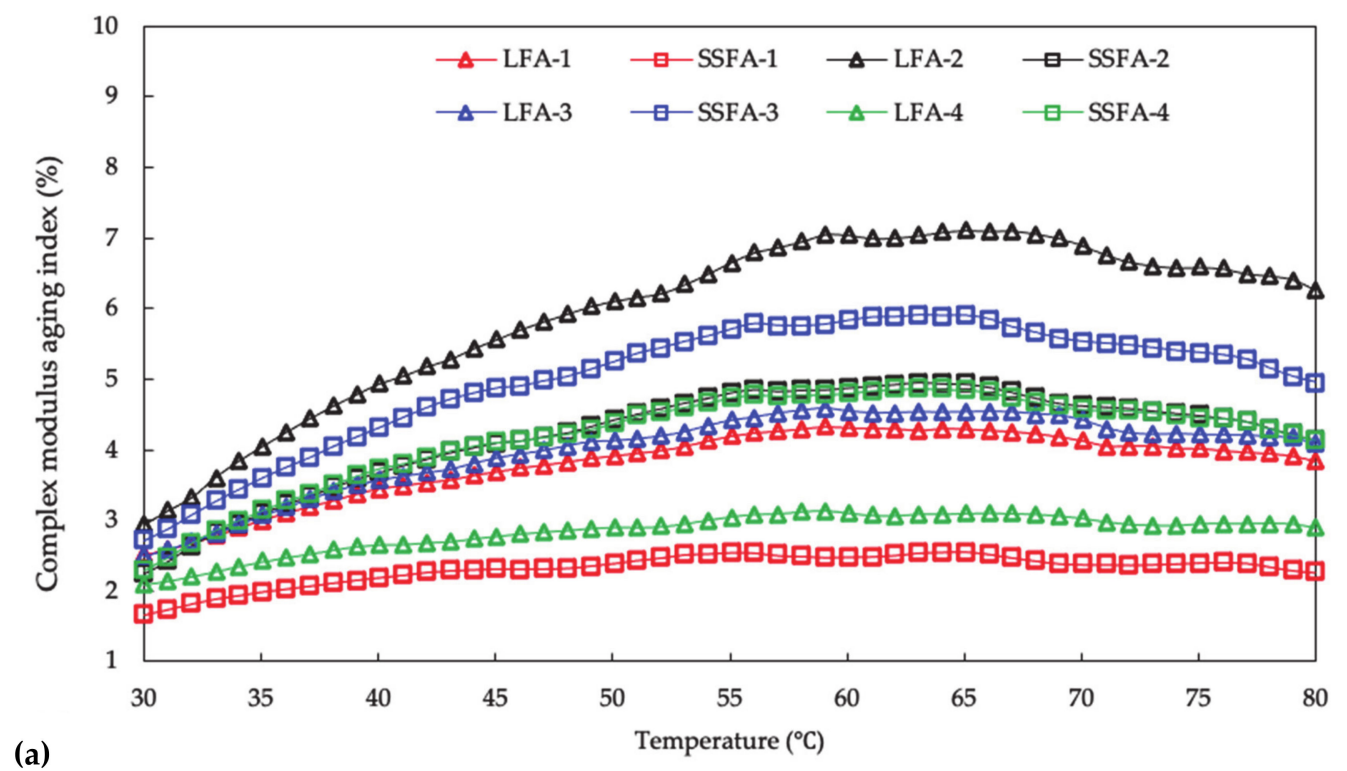

(a)

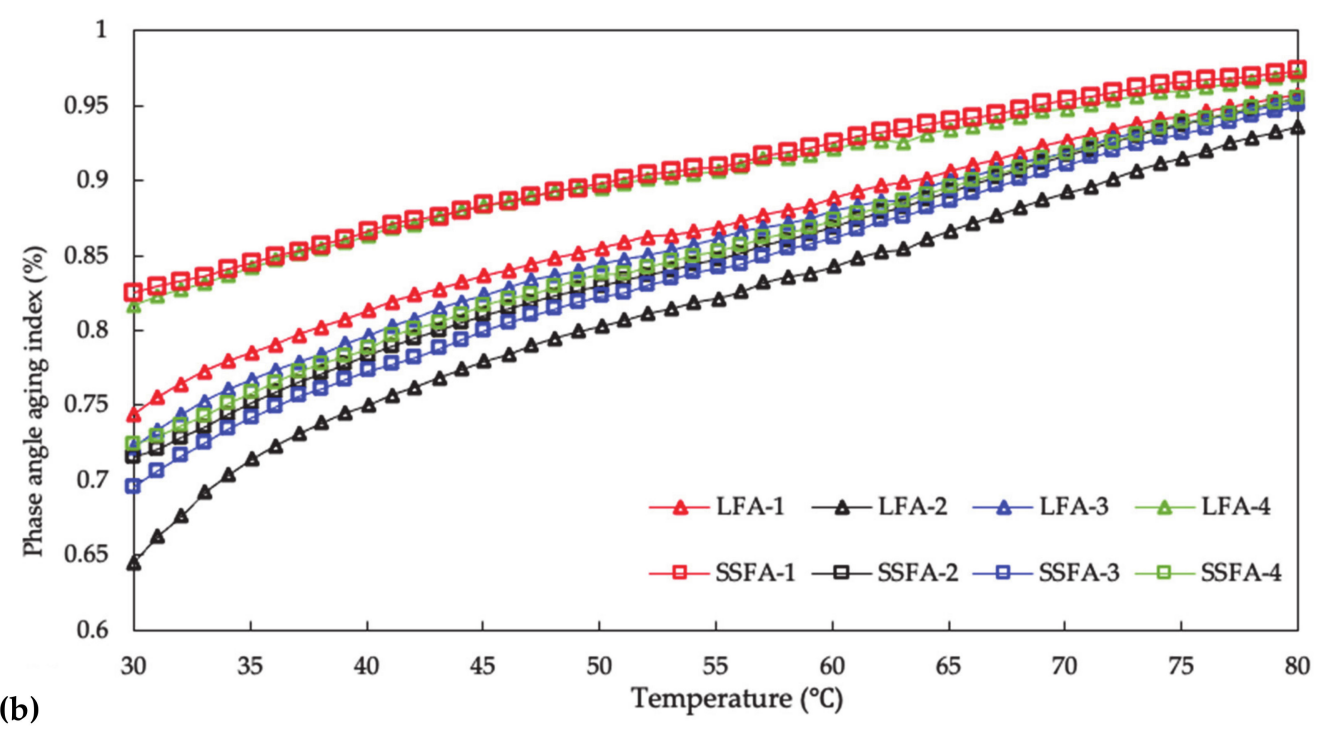

Figure 8. The changes of rheological properties of SSFA and LFA before and after solution aging. (a) Complex modulus aging index; (b) phase angle aging index. 
From Figure 8, after the same conditioning time, the order of the complex modulus aging index of SSFA is SSFA-3 $>$ SSFA-2 $>$ SSFA-4 $>$ SSFA-1; the order of the complex modulus aging index of LFA is LFA-2 > LFA-3 > LFA- $1>$ LFA- 4 . These tendencies are the same with the complex modulus.

The orders indicate the negative impact to the asphalt mastics of different solutions: $\mathrm{NaCl}$ solution > alkaline solution > pure water > acid solution (for SSFA); alkaline solution $>\mathrm{NaCl}$ solution > acid solution > pure water (for LFA). Moreover, the trend for the phase angle aging index corresponding to the negative impact are almost the same. Compared with LFA, SSFA presents a smaller complex modulus aging index and a larger phase angle aging index under the aging of acid solution and alkaline solution, whereas the opposite under the aging of $\mathrm{NaCl}$ solution and pure water. In summary, SSFA has a more outstanding performance in the environment of acid solution and alkaline solution but poor performance in the environment of $\mathrm{NaCl}$ solution and pure water than that of LFA.

The complex modulus and phase angles of SSFA and LFA conditioned by TFOT/UV/ TFOT+UV aging are shown in Figure 9. The results clearly demonstrate the diversity of the effect of the asphalt mastics. Under the three aging methods, the complex modulus of SSFA is all larger than that of LFA, meanwhile the order of the changing range of the phase angle is consistent with the complex modulus. UV aging methods witness the greatest deviation of the complex modulus, which indicates that the resistance to UV radiation of the asphalt mastics differed significantly. Moreover, the resistance to TFOT aging is posterior, and that of TFOT+UV aging is the least.

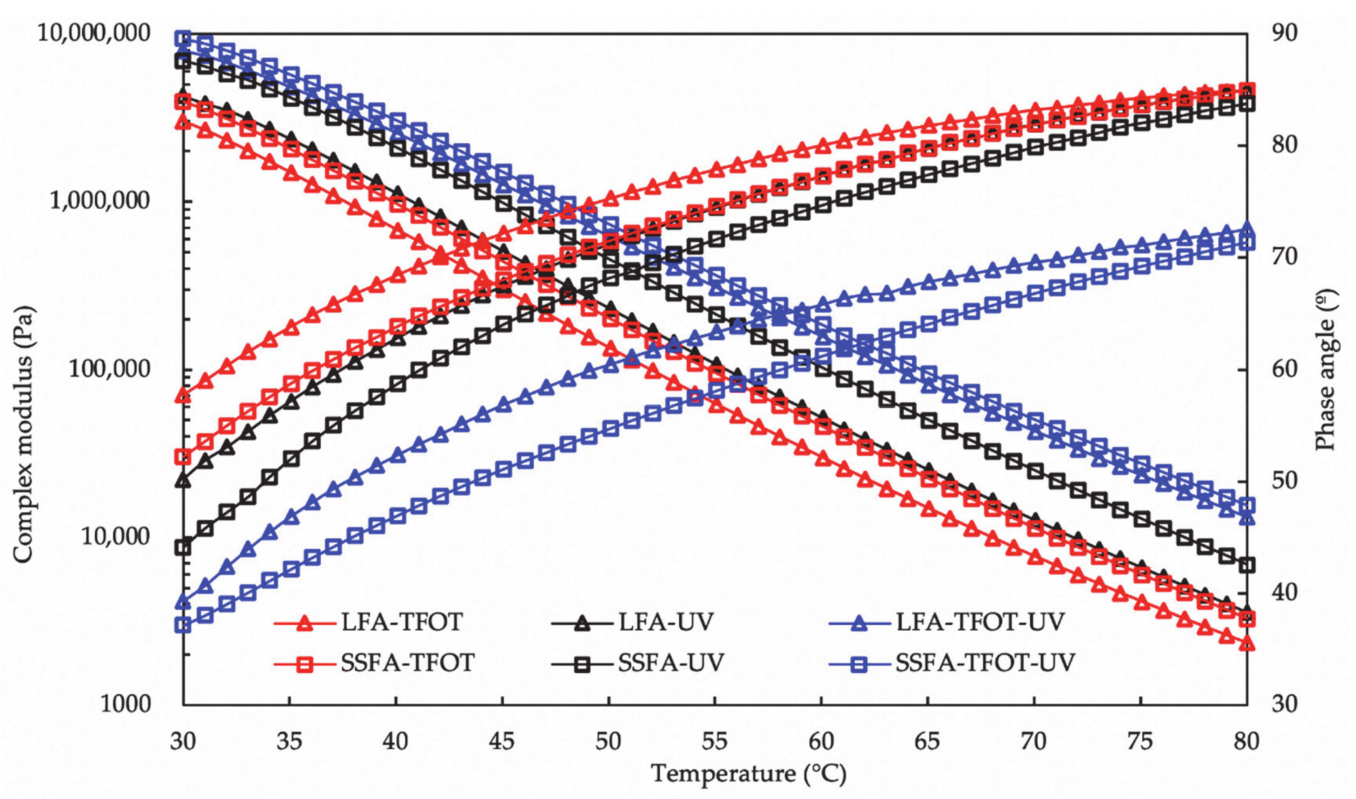

Figure 9. Temperature sweep analysis of SSFA and LFA after TFOT/UV/TFOT+UV aging.

The changes of rheological properties of SSFA and LFA before and after TFOT/UV/ TFOT+UV aging are shown in Figure 10. Similar to the results in Figure 8, with the increment of temperature, the complex modulus aging index shows a gradual upward trend from $30^{\circ} \mathrm{C}$, reaches a temporary peak at the range of $65^{\circ} \mathrm{C}$ to $75^{\circ} \mathrm{C}$, and then slightly decreases, under the aging methods of UV radiation and TFOT. In addition, the phase angle aging index also presents a similarity to that under solution aging. However, significant differences are recorded in the aging index under TFOT+UV aging method. The complex modulus aging index mounts up very quickly with the temperature increasing from $30^{\circ} \mathrm{C}$ to $80^{\circ} \mathrm{C}$ but reaches the highest level hardly. The reason for this behavior is related to the heavy aging degree that makes the temperature barrier rheological property hard to break. 

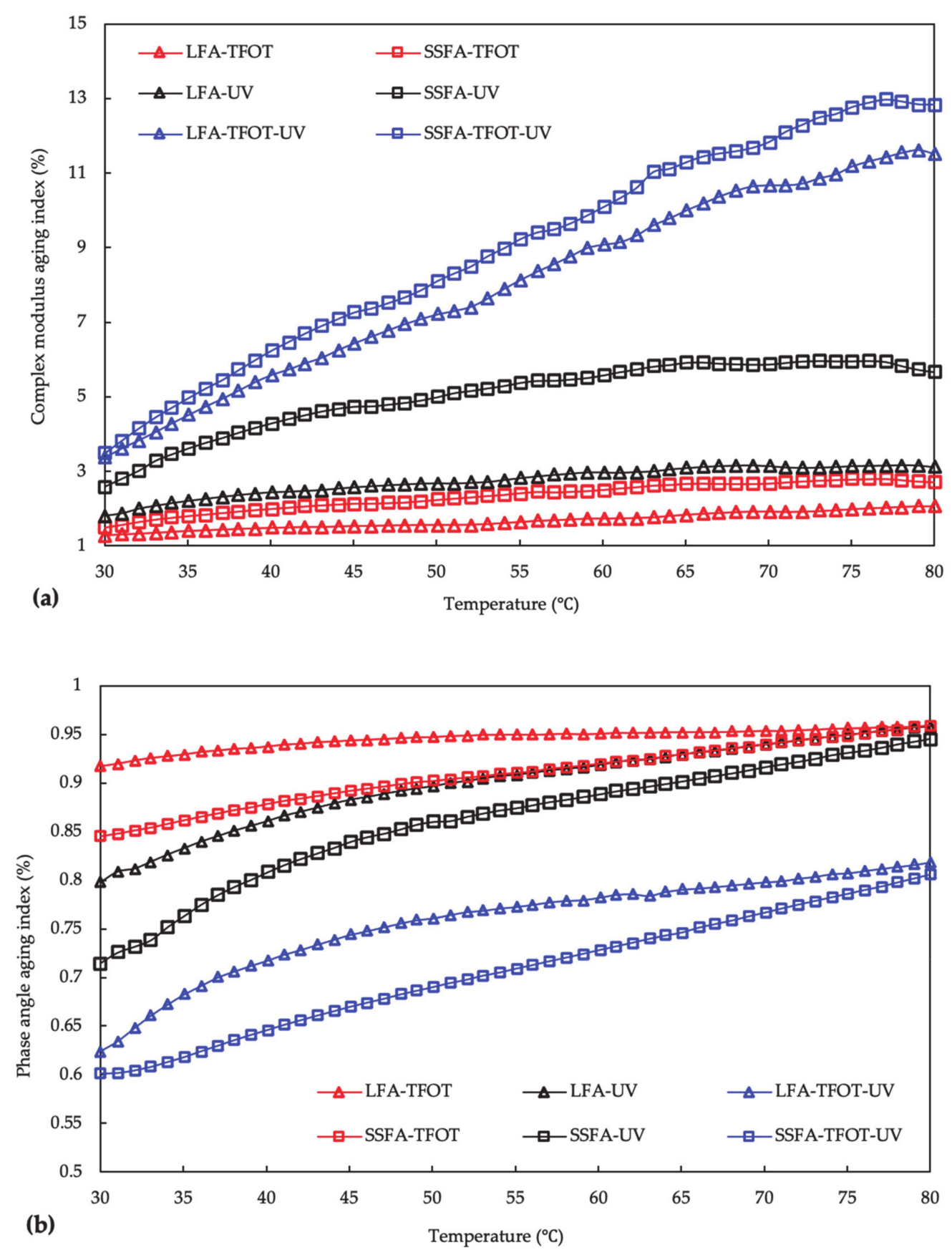

Figure 10. The changes of rheological properties of SSFA and LFA before and after TFOT/UV/TFOT+UV aging: (a) complex modulus aging index; (b) phase angle aging index.

Compared to LFA, the larger complex modulus aging index and smaller phase angle aging index of SSF are presented under all the three aging methods, which is accordant to the trend of temperature sweep analysis. Similarly, the complex modulus aging index under UV aging shows the greatest difference. The analysis results of Figure 10 reveal that the addition of SSF in bitumen performed poorly to resist the aging method of TFOT/UV/TFOT+UV, especially under UV radiation. This phenomenon could be correlated with the porous structure in SSF, which would cause multiple reflections of UV radiation then a heavier aging degree. Additionally, heat and oxygen are also accessed to pores more easily, resulting in a poor resistance to TFOT aging. 


\subsubsection{Self-Healing Properties}

The self-healing properties of the asphalt mastics are measured by frequency sweep and calculated by Equation (3), which represents the relationship between frequency and complex viscosity.

$$
\eta^{*}=m|f|^{n-1}
$$

In Equation (3), $f$ stands for the test frequency, $\eta^{*}$ stands for complex viscosity, $m$ and $n$ are the fitting parameters ( $n$ is also named the flow behavior index). When the parameter $\mathrm{n}$ is equal to 1.0, the measured asphalt mastics corresponds to Newtonian fluid, and when the parameter $\mathrm{n}$ is less than 1 , the measured asphalt mastics shows higher pseudoplasticity. When the flow behavior index is between 0.9 and 1 , samples can be regarded as close to Newtonian behavior. In this study, the temperature that corresponds to the flow behavior index equaling 0.9 is determined as the initial self-healing temperature.

The flow behavior indices of the asphalt mastics under different aging methods are shown in Figure 11. The calculation results show obvious deviations between SSFA and LFA. The flow behavior indices of SSFA are smaller than that of LFA under the aging methods of $\mathrm{NaCl}$ solution, pure water, TFOT, UV and TFOT+UV, while opposite under the aging methods of acid solution and alkaline solution. The definite initial self-healing temperatures of SSFA are $58{ }^{\circ} \mathrm{C}$ and $64^{\circ} \mathrm{C}$ under the aging methods of acid solution and alkaline solution, respectively. As for LFA, the temperature is around $79{ }^{\circ} \mathrm{C}$ under the aging methods of $\mathrm{NaCl}$ solution, pure water, TFOT and UV. Particularly, SSFA and LFA hardly reach 0.9 due to the fact that the aging degree of TFOT + UV is so heavy.
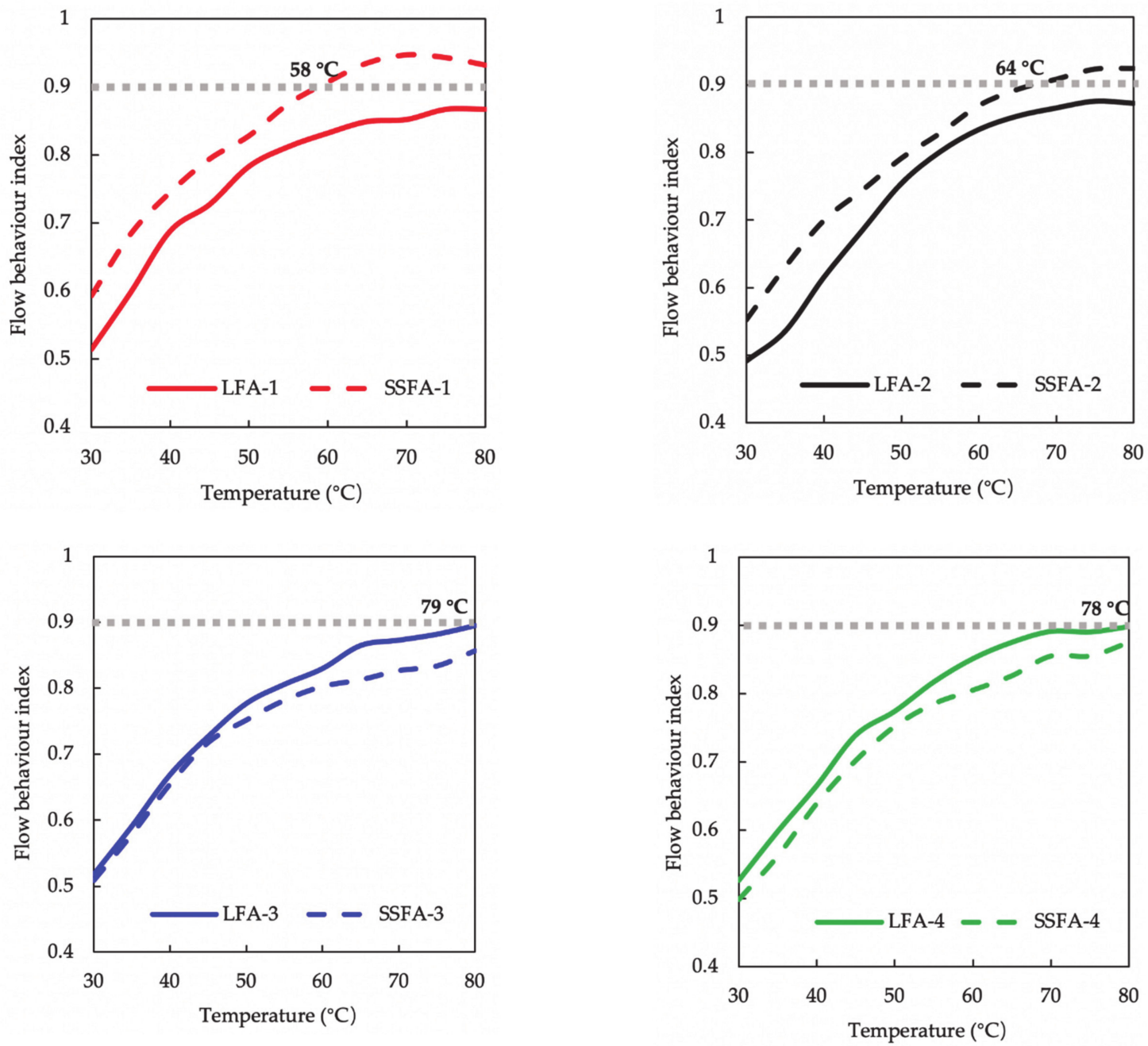

Figure 11. Cont. 

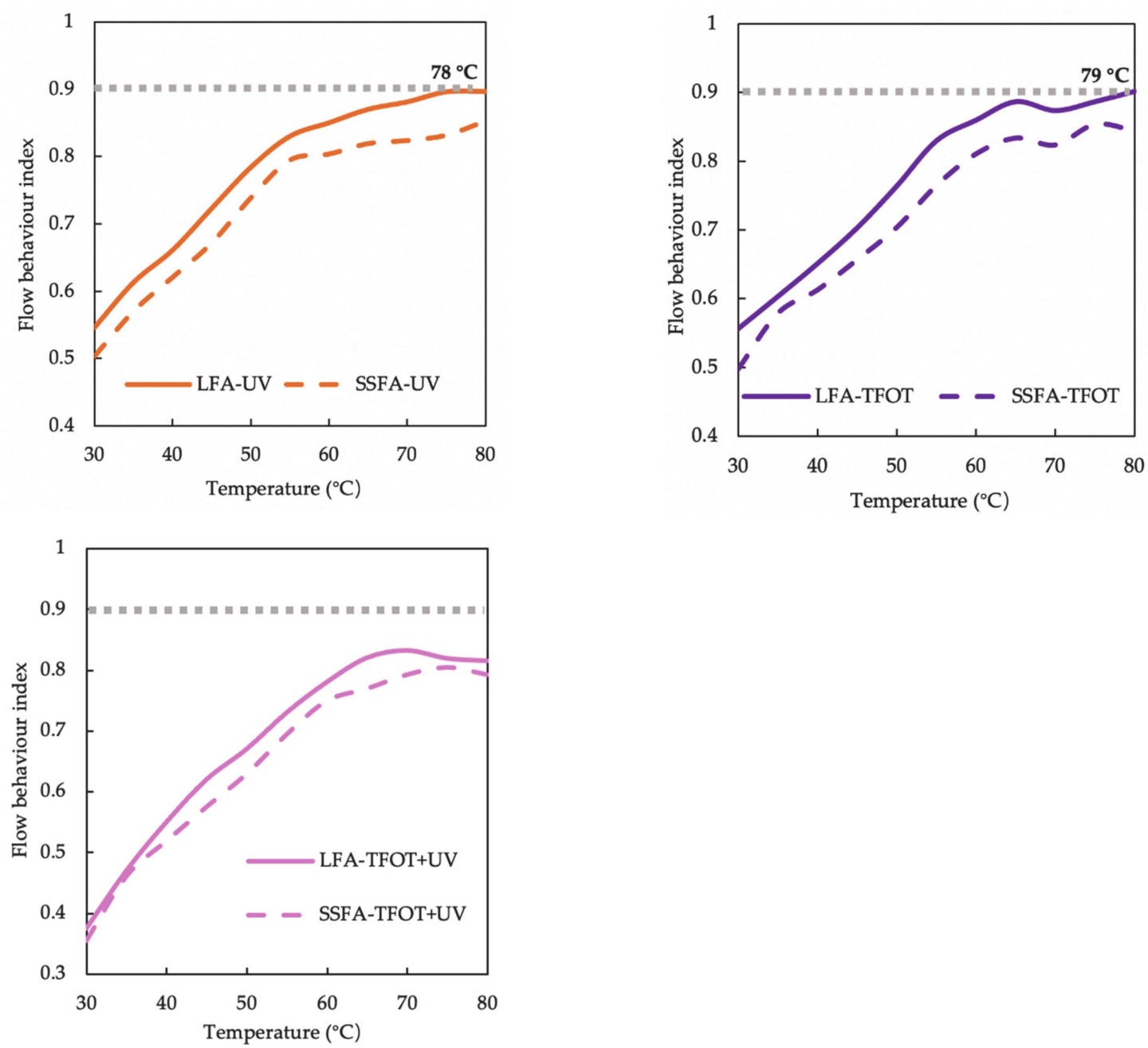

Figure 11. The comparison of SSFA and LFA in self-healing property under various aging methods.

\subsubsection{Chemical Functional Group Analysis}

The carbonyl functions $\mathrm{C}=\mathrm{O}$ (centered around $1700 \mathrm{~cm}^{-1}$ ) are monitored by studying their changes in spectra. The carbonyl functions $\mathrm{C}=\mathrm{O}$ can offer the information about oxidation of bitumen. The chemical functional group of bitumen in asphalt mastics can be evaluated by the relative contents of the carbonyl group $(\mathrm{C}=\mathrm{O})$ defined as Equation (4).

$$
I_{C=O}=\frac{A_{1703}}{\sum A}
$$

where $A_{1703}$ are the areas of the absorption bands at $1703 \mathrm{~cm}^{-1}, \Sigma \mathrm{A}$ is the sum of the areas of all the absorption bands.

From Figure 12, the order $I_{\mathrm{C}=\mathrm{O}}$ values of SSFA are $\mathrm{NaCl}>$ Alkali $>$ Acid $>$ Water and $\mathrm{TFOT}+\mathrm{UV}>\mathrm{UV}>\mathrm{TFOT}$ while the order $I_{\mathrm{C}=\mathrm{O}}$ values of LFA are Alkali $>\mathrm{NaCl}>$ Water $>$ Acid and TFOT+UV $>$ UV $>$ TFOT, indicating the hazard effect of these aging methods. In addition, $I_{\mathrm{C}=\mathrm{O}}$ values of SSFA are smaller than that of LFA under alkali solution and acidic solution. Generally, the molecules of bitumen would react with the acid solutions, which can take the hydrogen atoms away and expose the oxygen atoms, and in the alkaline solutions, carboxylic acids in the bitumen can make reaction with alkaline substance. However, the abundant $\mathrm{f}-\mathrm{CaO}$ in SSF tends to react with the components in the solutions faster than Fisher esterification and the neutralization reaction, preventing the aging to the bitumen. 


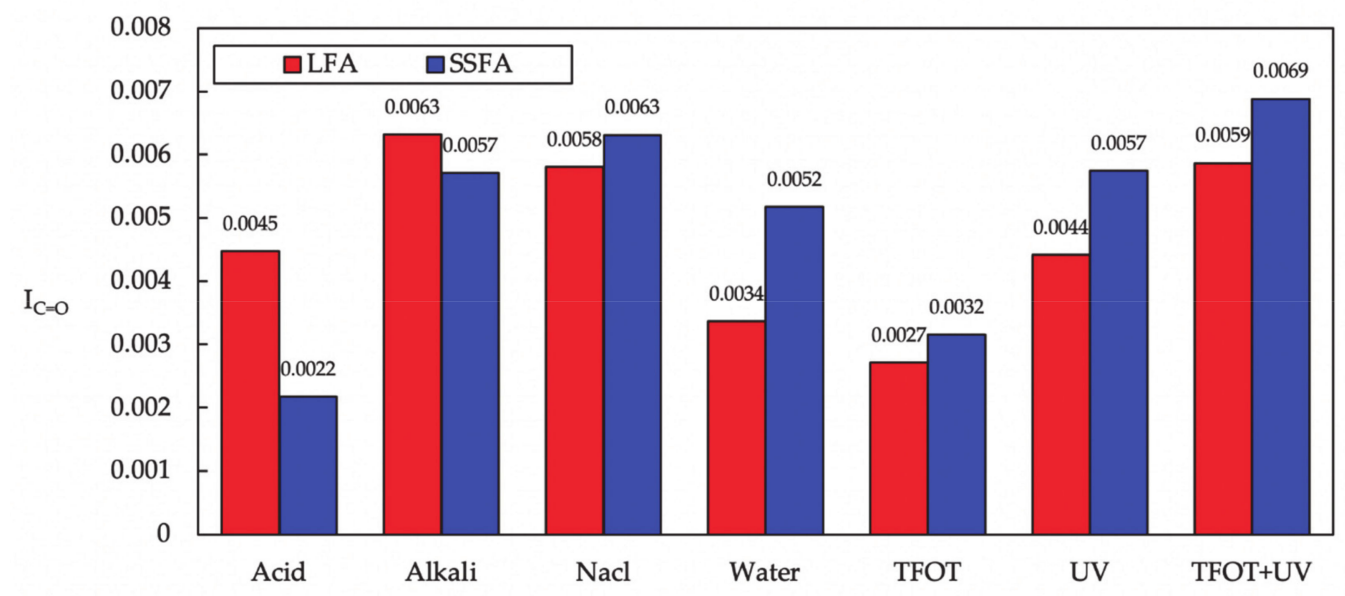

Figure 12. $\mathrm{I}_{\mathrm{C}=\mathrm{O}}$ of bitumen in asphalt mastic under different aging methods.

\section{Conclusions}

(1) In comparison of LF, characterization of SSF indicated similarity but more uniform in particle size distribution, which is related to the preparation methods of the fillers. On the contrary, distinction in surface characterization and pore characterization of the fillers differs significantly. SSF performs rougher surface and more abundant pore characterization, whereas LF has a relatively smooth surface and dull pore characterization.

(2) The addition of SSF and LF to asphalt binder results in an increment in the complex modulus and the properties of rutting resistance and fatigue resistance of asphalt mastic. The enhanced effect of SSF resembles that of LF, confirming the feasibility of replacement which was raised in previous research.

(3) Under the same condition of aging time, SSFA performs better in the environment of acid solution and pure water, worse in the environment of alkali solution and $\mathrm{NaCl}$ solution, as opposed to the performance of LFA. The enrichment of $\mathrm{f}-\mathrm{CaO}$ in SSF effects the orders of reaction with solutions, due to the fact that the $\mathrm{f}-\mathrm{CaO}$ tends to conduct the processing more easily.

(4) SSFA presents slightly poorer performance under the aging methods of TFOT/UV/ TFOT+UV compared to LFA, which is caused by the pore structure in SSF reflecting less energy and refracting more energy more easily. More consumption of bitumen has the potential to improve the impact, and effective measurement to delay the impact needs further investigation in future research.

Author Contributions: Conceptualization, H.L. and H.X.; data curation: M.W.; methodology, H.X.; validation, C.Y.; formal analysis, M.W.; investigation, H.L. and H.X.; writing-original draft preparation, M.W.; writing-review and editing, H.X. and C.Y.; supervision, S.W.; project administration, S.W.; funding acquisition, S.W. All authors have read and agreed to the published version of the manuscript.

Funding: This research was funded by the National Natural Science Foundation of China (No.7181101180 and No.51708437), Major Science and Technology Projects of Inner Mongolia Autonomous Region (zdzx2018029) and Hebei Provincial Communication Department project (YC-201926).

Data Availability Statement: The data presented in this study are available on request from the corresponding author.

Acknowledgments: The authors acknowledge Wuhan University of Technology for materials and experimental instrument support sincerely.

Conflicts of Interest: The authors declare no conflict of interest. 


\begin{tabular}{ll}
\multicolumn{2}{l}{ Abbreviations } \\
Acronyms & Full Name \\
LF & Limestone filler \\
SSF & Steel slag filler \\
VA & Virgin asphalt \\
LFA & Limestone filler asphalt mastic \\
SSFA & Steel slag filler asphalt mastic
\end{tabular}

\section{References}

1. Pan, P.; Wu, S.; Xiao, Y.; Liu, G. A review on hydronic asphalt pavement for energy harvesting and snow melting. Renew. Sustain. Energy Rev. 2015, 48, 624-634. [CrossRef]

2. Fang, C.; Yu, R.; Zhang, Y.; Hu, J.; Zhang, M.; Mi, X. Combined modification of asphalt with polyethylene packaging waste and organophilic montmorillonite. Polym. Test. 2012, 31, 276-281. [CrossRef]

3. Guo, M.; Tan, Y. Interaction between asphalt and mineral fillers and its correlation to mastics' viscoelasticity. Int. J. Pavement Eng. 2021, 22, 1-10. [CrossRef]

4. Li, S.; Ni, F.; Dong, Q.; Zhao, Z.; Ma, X. Effect of filler in asphalt mastic on rheological behaviour and susceptibility to rutting Int. J. Pavement Eng. 2021, 22, 87-96. [CrossRef]

5. Das, A.K.; Singh, D. Evaluation of fatigue performance of asphalt mastics composed of nano hydrated lime filler. Constr. Build. Mater. 2021, 269, 121322. [CrossRef]

6. Liu, B.; Wu, X.; Shi, J.; Wu, X.; Jiang, J.; Qin, J. Effect of cement as mineral filler on the performance development of emulsified asphalt concrete. Adv. Concr. Constr. 2020, 10, 515-526. [CrossRef]

7. Skaf, M.; Manso, J.M.; Aragón, Á.; Fuente-Alonso, J.A.; Ortega-López, V. EAF slag in asphalt mixes: A brief review of its possible re-use. Resour. Conserv. Recycl. 2017, 120, 176-185. [CrossRef]

8. Yang, C.; Xie, J.; Wu, S.; Amirkhanian, S.; Wang, Z.; Song, J.; Zhou, X.; Wang, F.; Zhang, L. Enhancement mechanism of induction heating on blending efficiency of RAP - virgin asphalt in steel slag recycled asphalt mixtures. Constr. Build. Mater. 2021, 269, 121318. [CrossRef]

9. Jiao, W.; Sha, A.; Liu, Z.; Li, W.; Jiang, W.; Qin, W.; Hu, Y. Study on thermal properties of steel slag asphalt concrete for snow-melting pavement. J. Clean. Prod. 2020, 277, 123574. [CrossRef]

10. Hu, R.; Xie, J.; Wu, S.; Yang, C.; Yang, D. Study of Toxicity Assessment of Heavy Metals from Steel Slag and Its Asphalt Mixture. Materials 2020, 13, 2768. [CrossRef] [PubMed]

11. Esther, L.-A.; Pedro, L.-G.; Irune, I.-V.; Gerardo, F. Comprehensive analysis of the environmental impact of electric arc furnace steel slag on asphalt mixtures. J. Clean. Prod. 2020, 275, 123121. [CrossRef]

12. Bessa, I.S.; Branco, V.T.F.C.; Soares, J.B. Evaluation of polishing and degradation resistance of natural aggregates and steel slag using the aggregate image measurement system. Road Mater. Pavement Des. 2014, 15, 385-405. [CrossRef]

13. Teixeira, J.E.S.L.; Schumacher, A.G.; Pires, P.M.; Branco, V.T.F.C.; Martins, H.B. Expansion Level of Steel Slag Aggregate Effects on Both Material Properties and Asphalt Mixture Performance. Transp. Res. Rec. J. Transp. Res. Board 2019, 2673, 506-515. [CrossRef]

14. Xue, Y.; Wu, S.; Hou, H.; Zha, J. Experimental investigation of basic oxygen furnace slag used as aggregate in asphalt mixture. J. Hazard. Mater. 2006, 138, 261-268. [CrossRef]

15. Cui, P.; Wu, S.; Xiao, Y.; Yang, C.; Wang, F. Enhancement mechanism of skid resistance in preventive maintenance of asphalt pavement by steel slag based on micro-surfacing. Constr. Build. Mater. 2020, 239, 117870. [CrossRef]

16. Guo, Y.; Wu, H.; Shen, A.; Yang, X.; Cui, T. Study of the long-term water stability of asphalt mixtures containing steel slag aggregate. J. Adhes. Sci. Technol. 2019, 34, 877-902. [CrossRef]

17. Amelian, S.; Manian, M.; Abtahi, S.M.; Goli, A. Moisture sensitivity and mechanical performance assessment of warm mix asphalt containing by-product steel slag. J. Clean. Prod. 2018, 176, 329-337. [CrossRef]

18. Chen, Z.; Xie, J.; Xiao, Y.; Chen, J.; Wu, S. Characteristics of bonding behavior between basic oxygen furnace slag and asphalt binder. Constr. Build. Mater. 2014, 64, 60-66. [CrossRef]

19. Cui, P.; Wu, S.; Xiao, Y.; Hu, R.; Yang, T. Environmental performance and functional analysis of chip seals with recycled basic oxygen furnace slag as aggregate. J. Hazard. Mater. 2021, 405, 124441. [CrossRef]

20. Li, C.; Chen, Z.; Wu, S.; Li, B.; Xie, J.; Xiao, Y. Effects of steel slag fillers on the rheological properties of asphalt mastic. Constr. Build. Mater. 2017, 145, 383-391. [CrossRef]

21. Tao, G.; Xiao, Y.; Yang, L.; Cui, P.; Kong, D.; Xue, Y. Characteristics of steel slag filler and its influence on rheological properties of asphalt mortar. Constr. Build. Mater. 2019, 201, 439-446. [CrossRef]

22. Kong, D.; Wu, S.; Chen, M.; Zhao, M.; Shu, B. Characteristics of Different Types of Basic Oxygen Furnace Slag Filler and its Influence on Properties of Asphalt Mastic. Materials 2019, 12, 4034. [CrossRef] [PubMed]

23. Li, C.; Wu, S.; Chen, Z.; Tao, G.; Xiao, Y. Enhanced heat release and self-healing properties of steel slag filler based asphalt materials under microwave irradiation. Constr. Build. Mater. 2018, 193, 32-41. [CrossRef]

24. Gong, B.; Wu, P.; Huang, Z.; Li, Y.; Yang, S.; Dang, Z.; Ruan, B.; Kang, C. Efficient inhibition of heavy metal release from mine tailings against acid rain exposure by triethylenetetramine intercalated montmorillonite (TETA-Mt). J. Hazard. Mater. 2016, 318, 396-406. [CrossRef] [PubMed] 
25. Bartoková, I.; Bott, A.; Bartok, J.; Gera, M. Fog Prediction for Road Traffic Safety in a Coastal Desert Region: Improvement of Nowcasting Skills by the Machine-Learning Approach. Bound. Layer Meteorol. 2015, 157, 501-516. [CrossRef]

26. Yuanyuan, L.; Hechuan, L.; Shuai, N.; Shaopeng, W.; Quantao, L.; Chuangmin, L.; Benan, S.; Chao, L.; Wei, S.; Yingxue, Z.; et al Negative impacts of environmental factors (UV radiation, water and different solutions) on bitumen and its mechanism. J. Constr. Build. Mater. 2020, 265, 120288.

27. Xie, X.; Li, H.; Duan, J.; Li, G.; Tong, S. Influence of the Mineral Powder Content on the Asphalt Aging Resistance in High-Altitude Areas Based on Indoor Ultraviolet Light Tests. Materials 2020, 13, 754. [CrossRef] [PubMed]

28. Ministry of Transport of the People's Republic of China. Standard Test Methods of Bitumen and Bituminous Mixtures for Highway Engineering; JTG E20; Ministry of Transport of the People's Republic of China: Beijing, China, 2011. (in Chinese)

29. Ministry of Transport of the People's Republic of China. Test Methods of Aggregate for Highway Engineering; JTG E42; Ministry of Transport of the People's Republic of China: Beijing, China, 2005. (in Chinese)

30. Cao, Z.; Chen, M.; Liu, Z.; He, B.; Yu, J.; Xue, L. Effect of different rejuvenators on the rheological properties of aged SBS modified bitumen in long term aging. Constr. Build. Mater. 2019, 215, 709-717. [CrossRef] 